\title{
Manipulation of Seedling Traits with Pulsed Light in Closed Controlled Environments
}

\author{
Shiwei Song ${ }^{1,2}$, Paul Kusuma $^{1}$, Sofia D. Carvalho ${ }^{1+},{\text { Yan } \mathrm{Li}^{1,3} \text { and Kevin M. Folta }}^{1,4}{ }^{*}$ \\ ${ }^{1}$ Horticultural Sciences Department, University of Florida, Gainesville, FL USA \\ ${ }^{2}$ College of Horticulture, South China Agricultural University, Guangzhou, China \\ ${ }^{3}$ College of Horticultural Science and Engineering, Shandong Agricultural University, Tai'an, \\ Shandong, China \\ ${ }^{4}$ Graduate Program in Plant Molecular and Cellular Biology, University of Florida, \\ Gainesville, FL USA
}

*Corresponding author: Phone: 352.273.4350, email address: kfolta@ufl.edu

${ }^{\dagger}$ Current address: Colegio de Ciencias Biológicas y Ambientales, Universidad San Francisco de Quito, Quito Ecuador

Keywords: microgreens, sprouts, kale, beet, LED, photomorphogenesis 


\section{Abstract}

2 There is substantial interest in growing crops in closed controlled environments, yet the energy

3 requirements are high. Energy is required to produce light, but also to remove the heat generated

4 when producing light. The goal of the current work examines a possible approach to decrease the

5 energy requirement. The effect of pulsed light treatments was examined by monitoring seedling

6 traits during early photomorphogenic development. Daily light integral remained unchanged

7 between treatments, but the frequency of the pulses was varied. Developmental traits (such as

8 inhibition of hypocotyl elongation rate) were most conspicuous during a normal photoperiod, as in

9 twelve hours light, twelve hours darkness. Consistent with historical reports, when treatments were

10 delivered in shorter durations (e.g. 1 hour on/off) photomorphogenic development was hindered,

11 with the same daily light integral. However, at even shorter light intervals (e.g. seconds) seedlings

12 developed as if they were provided full $12 \mathrm{~h}$ treatments. Extension of the dark period following a $5 \mathrm{~s}$

13 pulse was tested to determine the effect on seedling traits. The results showed that the dark period

14 could be extended to at least $10 \mathrm{~s}$ without affecting seedling development, and extension to $20 \mathrm{~s}$

15 only had slight effects on seedling traits. The mechanism of the phenomenon was examined in

16 Arabidopsis photosensory mutants, with substantial contributions from the phyA and cry1 pathways.

17 The results suggest that pulsed light with extended dark periods can decrease energy input by at

18 least $30 \%$ to $>50 \%$ without affecting visible seedling traits. These pilot experiments in seedlings

19 demonstrate that implementation of short-interval, pulsed-light strategies may lower energy

20 requirements for growing crops in artificially illuminated environments. 


\section{Introduction}

production. Crops raised inside closed controlled environments (CCE) offer the advantage of production of high-value specialty crops in or near population centers, a low carbon footprint relative to crops shipped over distance, the use of different crop protection strategies, and opportunities to conserve water and fertilizer [1, 2]. These approaches provide profitable nontraditional production of high-value specialty crops.

However, there are challenges to growing plants in CCE, including costs of initial investment and energy use. Depending on local economic situations, energy alone represents between 25\% [3] and $60 \%$ [4] of production costs, and they have a greater carbon footprint than traditional greenhouses [5]. These realities present bottlenecks to profitable production, as energy is needed for lighting as well as to dissipate the heat energy generated from light sources [reviewed in 6]. Light is required for plant growth via photosynthesis, but it also has an important role in shaping plant physiology, development, metabolism and morphology during the developmental program called photomorphogenesis [reviewed in 7, 8]. Because plants are rooted in one place, plants must continually monitor the ambient environment and adjust gene expression patterns to best acclimate to prevailing conditions $[9,10]$. The light environment is monitored through a series of specialized light sensors, each with an optimal range of activation, and each with downstream signaling pathways that terminate in mechanisms that shape plant biology. Over the last decade many reports have examined the effect of narrow-bandwidth spectrum, photoperiod and fluence rate with the intent of manipulating plant traits in controlled environments [11]. However, while control of light quantity and quality has become exquisite, the energy needs to drive plant production remain high.

Clearly light quantity (fluence rate), quality (wavelength), duration (photoperiod) can be altered individually or in combination to influence plant traits using today's sophisticated technologies. In this report we revisit another variable-the frequency of pulses applied in intervals 

indistinguishable from a normal 12 hour dark-light photoperiod [14]. savings by extending the dark period between pulses. The hypothesis is that a defined frequency of

54 pulses may lead to production of identical plant products with fewer photons invested. These experiments exploit two factors not available to Garner and Allard in 1931-- the known plasticity of

57 these three tools have been combined to examine the effects of light pulses on growth and

58 development, with special attention to the length of the dark period between pulses. Consistent

59 with eighty-eight-year-old observations using full-spectrum white light [14], the results indicate that

60 seedlings treated with pulse light for several seconds are indistinguishable from those treated with a

61 normal photoperiod. Examination of the dark interval shows that it may be extended without

62 affecting seedling development for well past the equivalent seconds-long treatment to obtain the

63 same effect from one $12 \mathrm{~h}$ light treatment. The use of pulsed light with extended dark periods

64 provides an additional tool to manipulate plant growth and development, and may provide energy

65 savings by supporting comparable growth with significantly lower daily light integrals. 


\section{$67 \quad$ Materials and Methods}

Plant Materials

Red Russian Kale, Purple Top Turnip, and Ruby Queen Beet Seeds were purchased from Johnny's

Selected Seeds (Fairfield, ME). Arabidopsis experiments were performed with seedlings in the

71 Columbia (Col-0) background. Experiments for cryptochrome (cry1-304 and cry2-1) mutants were

the Lansberg erecta (Ler) background.

\section{Growth and assay conditions}

Survey experiments were performed on seeds placed on autoclaved BioStrate Felt saturated

with $0.1 x$ Hoaglands basal salt hydroponic solution inside glass, wide-mouth, pint canning jars

covered with the lower half of a plastic petri dish. The seeds were stratified in darkness at $4^{\circ} \mathrm{C}$ for 72

$\mathrm{h}$, and then transferred to room temperature $\left(22^{\circ} \mathrm{C} \pm 2^{\circ}\right)$ and exposed to cool white fluorescent light

$80\left(15 \mu \mathrm{mol} \mathrm{m} \mathrm{m}^{-2}\right)$ for $1 \mathrm{~h}$, and then moved into complete darkness for a minimum of $2 \mathrm{~h}$ before being

transferred to the specific light treatment. 
$\mathrm{nm}$ (red; R), and 730nm (far-red; FR). For some light pulse experiments both a GRALab model 655

Anthocyanin $/ \mathrm{mg}$ FW tissue $=\left(\left(\mathrm{Abs}_{530}-\mathrm{Abs}_{657}\right) \times 1000\right) /$ powder weight $(\mathrm{mg})$

\section{Statistical analysis}

114 All experiments were repeated at least three times. Statistical analyses were performed using the 115 statistical software package SPSS 19.0 (SPSS, Inc., Chicago, IL, USA). Data were analyzed by one-way 116 analysis of variance with LSD method. 
117

Results

\section{Developmental Response to Light Treatment}

To examine the effect of different light pulse lengths at a common daily light integral (DLI), seedlings from three genotypes were placed into chambers and treated with various fluence rates of far-red light. FR was chosen because it induces strong responses in Red Russian kale and is widely recognized for its strong effect on inhibition of hypocotyl elongation and anthocyanin accumulation [16]. At the same time FR light sources do not significantly excite photosynthesis, so using these wavebands allows uncoupling of developmental response from influences arising from chloroplast development and photosynthesis. Seedlings were grown for $96 \mathrm{~h}$ under pulses of FR light, varying from $5 \mathrm{~s}$ to $12 \mathrm{~h}$, all with a fluence rate $100 \mu \mathrm{mol} \mathrm{m}^{-2} \mathrm{~s}^{-1}$ and DLI of $4.32 \mathrm{~mol} \mathrm{~m}^{-2}$. The results are presented in in Figure 1.

The results show that in Red Russian Kale and Purple Top Turnip seedlings accumulate anthocyanins in a $12 \mathrm{~h}$ (on/off) light interval. As the light interval is split into smaller time periods there is less accumulation as pulse times decrease from $6 \mathrm{~h}$ down to $1 \mathrm{~min}$, with the lowest accumulation occurring between $30 \mathrm{~min}$ and $1 \mathrm{~h}$. Light pulses of $30 \mathrm{~s}$ and under led to the same amount of anythocyanin (or possibly more) as a $12 \mathrm{~h}$ treatment. The Ruby Queen beet also exhibited a similar trend, but the absolute levels of anthocyanin were higher than in the other two seedlings. Further experiments would focus only on kale and the turnip seedlings.

A similar trend was observed for hypocotyl elongation (Figure 1). Seedlings grown under longer intervals that approximate normal day/night intervals exhibited the shortest hypocotyls, with the longest hypocotyls typically occurring in response to pulses from $10 \mathrm{~min}$ to $1 \mathrm{~h}$. However, shorter pulses $(5,10,30 \mathrm{~s})$ produce the same outcomes as the longer 12 -h pulse.

Fresh weight, chlorophyll accumulation and anthocyanin accumulation were all measured under these conditions. All of these measurements showed trends in response to light that were highly similar to those observed for hypocotyl length (K. Folta, P. Kusuma; Unpub. obs.). These observations indicated that hypocotyl elongation was a suitable proxy for measuring 
photomorphogenic progression. Further experiments would focus strictly on hypocotyl growth inhibition under various light treatments.

145

\section{Persistence of Light Response}

The data from Figure 1 show that seedlings receiving the same DLI spread over $12 \mathrm{~h}$ or $5 \mathrm{~s}$

intervals are comparable in terms of development and physical attributes. It was therefore of

interest to examine the persistence of the light effect after the light pulse ended, and determine

how long the dark period may be extended before the photomorphogenic development slowed. At

the same time, growth under different wavebands may inform how different photosensory systems

Figure 2.

$B$ and $R$ light effects on hypocotyl growth inhibition begin to revert $10 \mathrm{~s}$ after a $5 \mathrm{~s}$ pulse in

both kale and turnip. The effect of FR illumination was more persistent, as growth inhibition did not

revert significantly until after $20 \mathrm{~s}$ of darkness in kale, and small (yet statistically significant)

differences were seen in turnip seedlings after a $10 \mathrm{~s}$ dark period. A combination of light inputs $(B=$

$30 \mu \mathrm{mol} \mathrm{m} \mathrm{s}^{-2}, \mathrm{R}=110 \mu \mathrm{mol} \mathrm{m} \mathrm{s}^{-1}, \mathrm{FR}=30 \mu \mathrm{mol} \mathrm{m}^{-2} \mathrm{~s}^{-1}$ ) provided stronger inhibition that persisted

until after $10 \mathrm{~s}$, but was still comparable to single-waveband $5 \mathrm{~s}$ dark treatments after $20 \mathrm{~s}$ of

darkness. Trends of anthocyanin and chlorophyll accumulation were similar, indicating that the in response to light. 
the same pulse conditions in Figure 3. Repeating the experiments in Arabidopsis allows examination

of the response in a well-characterized physiological system and opens the possibility to examine

mutant genotypes that may aid in understanding the genetics of persistent light signaling when plants are treated with extended dark periods.

The results in Figure 3 show the Arabidopsis (Col-0) response to pulse light with increasing

To the contrary, $\mathrm{R}$ light pulses had a much lower effect on growth inhibition in amplitude, yet the effects were persistent even at low fluence rates. The effects of FR light pulses were much like those of B light, with a strong effect on growth inhibition that was maintained after $20 \mathrm{~s}$ of darkness, even at low fluence rates. At $100 \mu \mathrm{mol} \mathrm{m} \mathrm{m}^{-2}$ the inhibition was persistent, unchanged after $40 \mathrm{~s}$ of darkness, and maintaining the majority of growth inhibition even up to $160 \mathrm{~s}$ of dark period.

\section{Genetic Analysis}

The experiments outlined in Figure 3 indicate that different photosensory systems vary in maintaining the response to the pulse treatment. The mechanism can be better explored using photomorphogenic mutants in Arabidopsis. The experiments in Figure 3 were repeated using coirradiation with $\mathrm{R}, \mathrm{B}$ and $\mathrm{FR}$ light, tested on the phyA, phyB, cry1, and cry 2 mutants and their corresponding wild-type genotypes. Three wavebands were delivered simultaneously (as described above) to observe the effects of coaction. The results are shown in Figure 4. 
194 wavebands in combination, reaching what appears to be full inhibition and retaining hypocotyl

growth inhibition at least until $40 \mathrm{~s}$ of darkness. Examination of photomorphogenic mutants shows 


\section{Discussion}

206 The realistic potential of closed controlled environment (CCE) agriculture is limited by several factors, which include high costs of energy for illumination and temperature management

[17]. The adoption of these technologies is tightly tied to grower profit, and that is substantially

Several strategies have been proposed to decrease the energy demands of CCE. Plant high intensity white light, with light/dark intervals ranging from $6 \mathrm{~h}$ down to seconds. The authors observed that plants treated with intervals from $1 \mathrm{~h}$ to $1 \mathrm{~min}$ performed poorly and exhibited symptoms of malnutrition, such as less chlorophyll and less accumulation of dry matter. However, plants grown under $5 \mathrm{~s}$ intervals performed the same as normal $12 \mathrm{~h}$ photoperiod controls [14]. In 
In the present study the principles of this seminal work were applied to developing

seedlings. The work used seedlings because the developing seedling is exquisitely sensitive to light

signals. Light sensing, integration and response results in conspicuous morphological, molecular and

biochemical changes that may be easily monitored and measured. Traits such as inhibition of

hypocotyl elongation, light mediated gene expression and the accumulation of photosynthetic or

screening pigments are closely tied to light input, and respond proportionately over a large range of

fluence rates and wavelengths. The experiments may be performed over the course of $96 \mathrm{~h}$, allowing

later be tested in mature crop plants.

The species tested offer specific strengths and limitations. Red Russian Kale and Purple Top

Turnip have been previously characterized and possess several conspicuous seedling responses to

light across the spectrum, with a long range of linear response to varying fluence rates (P. Kusuma,

K. Folta, unpub. obs.). While performing well in these experiments, the selection of two highly-

plastic brassicas frames a central limitation to interpreting the results of the trials, as it is unclear

how such treatments translate to distant taxa. The findings did translate well to two Arabidopsis

thaliana ecotypes. While still brassicas, they are not crop plants, so it suggests that the ability to

integrate an intermittent light signal is not something that arose from selection and is likely inherent

to seedlings, at least within brassicas. Future experiments will test these responses in other

important seedling varieties used as commercial food crops as well as in mature plants.

The basic experiments show that seedlings grown under $5 \mathrm{~s}$ on/off pulse are roughly comparable developmentally to seedlings grown under $12 \mathrm{~h}$ on/off pulses (Figure 1). The DLI is exactly the same at a given fluence rate $\left(4.32 \mathrm{~mol} \mathrm{~m}^{-2}\right)$. Intervals that are $30 \mathrm{~min}$ or $1 \mathrm{~h}$ min long show less photomorphogenic advancement, despite treatment with the same DLI. As treatment durations increase to 3 and $6 \mathrm{~h}$, plants show more photomorphogenic progression, before reaching 
254 development reflect effects of the timing of light/dark cycles. These findings begin to touch on the

255 mechanism for how pulsed treatments work, as these results indicate that seedlings must have a

256 means to gate light input into developmental processes that limits signals when they are delivered in 257 pulses that are $30 \mathrm{~min}$ to $1 \mathrm{~h}$ in duration.

A good candidate might be components that input into the circadian oscillator. For instance, the Evening Complex [21] is a multi-protein complex formed from interaction of EARLY FLOWERING3 [22] EARLYFLOWERING4 and LUXARRYTHMO [23]. It is expressed rhythmically and interacts with phyB. Ultimately the complex connects the internal oscillator to processes such as expression of genes associated with photosynthesis and plant growth. Developing seedlings with defects in the

Evening Complex exhibit longer hypocotyls $[23,24]$. The hypothesis is also consistent with the concept of "gating", a process where a response cannot be activated because a molecularbiochemical constraint restricts the magnitude of circadian-oscillator conditioned responses [25].

It is tempting to speculate that short pulses are insufficient to condition the oscillator (override the gate), so from a photosensory viewpoint seedlings interpret short (seconds) pulses as constant light. However, when pulses reach $30 \mathrm{~min}$ to several hours in duration it is sufficient to set the biochemical complexities of the internal oscillator in motion, only to be disturbed by an unexpected period of darkness. The chloroplast also may be disturbed, as photosynthetic rates and partitioning of resources now occurs in intervals that are not in concert with the internal oscillator. 
light signaling after treatment. Far-red light has been shown to exert powerful effects on inhibition of stem elongation $[26,27]$ and also promotes anthocyanin accumulation $[28-30]$, and therefore is a way to uncouple developmental cues from photosynthetic influence. The effects of pulses on these processes confirms that at least part of the effect being observed is due to excitation of photomorphogenic systems, namely phyA. The cry1 receptor has been shown to be active for at least six minutes [31]. The persistence of a response to a $5 \mathrm{~s}$ pulse after $80 \mathrm{~s}$ darkness demonstrates that all relevant photoreceptors are saturated and excess energy is not able to contribute to the response. In photobiological terms reciprocity failure observed, as there is a non-linear response between photons applied and response measured. The likely cause is the molecular or physiological bottleneck that occurs when the seedling cannot sense, signal, or respond any further to an increasing level of input. This is an important threshold to understand, as energy applied once the plants have achieved a full response is essentially wasted.

This information is important in the design of artificial lighting environments. At least in seedlings under B, R and FR treatment, the coaction of multiple sensory systems leads to a more complete suppression of hypocotyl elongation than any single treatment alone. Figure 2 shows that the combination of $B, R$ and FR leads to inhibition that is stronger than any single waveband, although the influence of the signal wanes after $10 \mathrm{~s}$ of darkness, and seedlings were substantially longer with $20 \mathrm{~s}$ of darkness following the light treatment. Supplemental Figure 1 shows the effects on pigments, as anthocyanin and chlorophyll levels slow diminish with the extended dark period, yet not to the degree that hypocotyl elongation rate is affected. It also is important to note that both Red Russian Kale and Purple Top Turnip were likely selected because of their purple color, so anthocyanin levels may be expected to be high. There may be much less in other seedling varieties, but the results show that many traits may still be maintained through significant periods of darkness. Such findings could have a profound effect on energy savings if implemented in production contexts. 
The same responses were tested in the model plant Arabidopsis thaliana. These tests were appropriate because of the substantial photophysiological and genetic understanding of inhibition of stem elongation in the species. The results of narrow-bandwidth light treatments indicate that a relatively low fluence rate treatment of $10 \mu \mathrm{mol} \mathrm{m} \mathrm{m}^{-2} \mathrm{~B}$ or FR light can strongly inhibit stem elongation, and that the response persists even after 40 and 80 s respectively. Treatment with 100 $\mu \mathrm{mol} \mathrm{m} \mathrm{m}^{-2} \mathrm{~s}^{-1}$ leads to potent suppression that persists even after $160 \mathrm{~s}$ for both wavelengths. The data indicate that the treatments approximate a dose-response relationship over a limited number of points tested. More importantly, a $5 \mathrm{~s}$ pulse of FR light at $1 \mu \mathrm{mol} \mathrm{m} \mathrm{s}^{-2}$, applied every $15 \mathrm{~s}$ is sufficient to suppress stem elongation almost maximally. These findings introduce the basis of examining the photon economy of plant development, as a relatively low fluence rate treatment more frequently may be more effective than a less-frequent high-fluence-rate pulse.

The results also show that $\mathrm{R}$ light sensing systems are less responsive than $\mathrm{FR}$ or $\mathrm{B}$. Strong effects of $\mathrm{R}$ light on hypocotyl elongation rate are only seen with frequent pulses of high fluence rate light. At least with respect to Arabidopsis seedlings, and the limited data from kale and turnips, these results suggest that $\mathrm{R}$ light may be dispensable in maximizing early developmental response to light. B and FR light are more potent per photon delivered, which is an important consideration in the design of lighting regimes for plant growth. Light sources for these wavebands have approximately the same output in terms of photons per joule (Pattison et al., 2018), with substantial differences in how that energy investment translates to plant development. An energy honing strategy may be to provide a $1 \mu \mathrm{mol} \mathrm{m} \mathrm{m}^{-1}$ pulse of FR light every $10 \mathrm{~s}$, and a $10 \mu \mathrm{mol} \mathrm{m} \mathrm{m}^{-2} \mathrm{~s}^{-1}$ of $\mathrm{B}$ light every $40 \mathrm{~s}$. Robust suppression of stem elongation rate is achieved with fewer photons invested that is similar to a single daily high-fluence-rate $12 \mathrm{~h}$ treatment.

The results are consistent with what is observed in genetic analyses, which were performed on seedlings grown under blue, red and far-red light in combination. The results in Figure 4 show that elimination of cry1 leads to reversion of the sustained inhibition, and that cry2 has little 
328 influence. With respect to phytochromes, phys appear to be acting redundantly, and even the 329 phyАphyB mutant shows inhibition after $10 \mathrm{~s}$ of darkness, likely an effect imparted by cry1. It is also 330 worth noting that elimination of phyA leads to stronger growth inhibition after $80 \mathrm{~s}$ of darkness, suggesting a role in growth promotion that is opposing the effect of phy $\mathrm{B}$, and other receptors. will examine if pulsed-light treatments can drive production of microgreens or even leafy greens 334 with results comparable to normal-photoperiod plants. Even if the principles shown here fail to 335 translate to mature crops the use of light interval treatments clearly is effective in seedlings, and the 336 capacity to conserve energy during establishment is still an important gain even if the plants require 337 normal photoperiodic treatments going forward. It also may be possible to select specific varieties 338 that perform well under these light-dark treatments with extended dark periods. In all cases these 339 seconds-long pulses may be one other way to limit the cost of production in closed, controlled environments. 


\section{$341 \quad$ Acknowledgements}

342 The authors thank the Chinese Scholarship Council for supporting the visiting scientist appointment

343 of SS. SC'S postdoctoral appointment was funded by the United States Department of Agriculture

344 Grant number. We thank by Light Emitting Computers (Victoria, BC Canada) for providing summer

345 salary for PK. We present this work in memory of LEC founder Jeffery Bucove who shared a vision of

346 using artificial lighting strategies to improve plant production to aid the human condition. 


\section{$348 \quad$ Figure Legends}

349 Figure 1. Light pulse frequency effects in select seedlings. Inhibition of hypocotyl elongation and 350 anthocyanin accumulation were assessed in seedlings of Red Russian Kale, Purple Top Turnip, and 351 Ruby Queen Beet in response to $10 \mu \mathrm{mol} \mathrm{m} \mathrm{s}^{-1}$ far red light, applied for various time intervals for $35296 \mathrm{~h}$. The mean represents measurements from one experiment with at least 30 seedlings.

353 Independent experiments were performed with similar results. Error bars represent standard error 354 of the mean.

355 Figure 2. The effect of extending the dark period following a light pulse in Red Russian Kale and 356 Purple Top Turnip. Inhibition of hypocotyl elongation was assessed in response to $100 \mu \mathrm{mol} \mathrm{m} \mathrm{m}^{-2}$ 357 blue, red, far-red, or combination ( $B: R: F R=1: 4: 1 ; \sim 140 \mu \mathrm{mol} \mathrm{m}^{-2} \mathrm{~s}^{-1}$ ) light, followed by a dark period 358 ranging from 5 to $160 \mathrm{~s}$ for $96 \mathrm{~h}$. For each experiment $\mathrm{N}>20$ seedlings and the mean reflects the 359 results of three independent experiments. Error bars represent the standard error of the mean.

360 Different letters represent significant differences by LSD ANOVA analysis $(p<0.05)$.

361 Figure 3. Wavelength dependence and fluence-rate/response effect on hypocotyl inhibition.

362 Arabidopsis thaliana seedlings were germinated and grown under various pulse conditions under 363 various fluence rates of blue, red or far-red light. Light pulses were applied for $5 \mathrm{~s}$ and the dark 364 interval varied. Hypocotyl lengths were assessed after $96 \mathrm{~h}$. The means represent outcomes from 365 three independent experiments ( $>20$ each). Error bars represent the standard error of the mean. 366 Different letters represent significant differences by LSD ANOVA analysis $(p<0.05)$.

Figure 4. The effect of light pulse persistence in Arabidopsis mutants and corresponding wild-type plants. Arabidopsis seedlings were grown under a combination of blue, red, and far-red light (1:4:1) and a fluence rate of $\sim 140 \mu \mathrm{mol} \mathrm{m} \mathrm{m}^{-2}$, pulsed for five seconds with a variable dark period. The data 


\section{Supplemental Figure}

380 Supplemental Figure 1. The effect of extending the dark period on pigment accumulation in Red

381 Russian Kale and Purple Top Turnip. Anthocyanin and chlorophyll accumulation levels were anlayzed

382 in response to $100 \mu \mathrm{mol} \mathrm{m} \mathrm{s}^{-2} \mathrm{~s}^{-1}$ blue, red, far-red, or combination (B:R:FR=1:4:1; 140 $\mu \mathrm{mol} \mathrm{m}^{-2} \mathrm{~s}^{-1}$ )

383 light, followed by a dark period ranging from 5 to $160 \mathrm{~s}$ for $96 \mathrm{~h}$. For each experiment $\mathrm{N}>6$ seedlings

384 and the mean reflects the results of three independent experiments. Error bars represent the

385 standard error of the mean. Different letters represent significant differences by one-way ANOVA

386 with Tukey HSD post-hoc test $(p<0.05)$. 


\section{Literature Cited}

[1] M. Al-Chalabi, Vertical farming: Skyscraper sustainability?, Sustainable Cities and Society, 18 (2015) 74-77.

[2] D. Despommier, The vertical farm: controlled environment agriculture carried out in tall buildings would create greater food safety and security for large urban populations, Journal für Verbraucherschutz und Lebensmittelsicherheit, 6 (2011) 233-236.

[3] T. Kozai, Sustainable plant factory: Closed plant production systems with artificial light for high resource use efficiencies and quality produce, in, pp. 27-40.

[4] C. Zeidler, D. Schubert, V. Vrakking, Feasibility study: vertical farm EDEN, (2013).

[5] K. Harbick, L.D. Albright, Comparison of energy consumption: greenhouses and plant factories, in, pp. 285-292.

[6] T. Kozai, G. Niu, M. Takagaki, Plant factory: an indoor vertical farming system for efficient quality food production, Academic Press, 2015.

[7] C. Kami, S. Lorrain, P. Hornitschek, C. Fankhauser, Light-regulated plant growth and development, Curr Top Dev Biol, 91 (2010) 29-66.

[8] M. de Wit, V.C. Galvao, C. Fankhauser, Light-Mediated Hormonal Regulation of Plant Growth and Development, Annu Rev Plant Biol, 67 (2016) 513-537.

[9] J.A. Sullivan, X.W. Deng, From seed to seed: the role of photoreceptors in Arabidopsis development, Dev Biol, 260 (2003) 289-297.

[10] P. Lymperopoulos, J. Msanne, R. Rabara, Phytochrome and Phytohormones: Working in Tandem for Plant Growth and Development, Front Plant Sci, 9 (2018) 1037.

[11] P.M. Pattison, J.Y. Tsao, G.C. Brainard, B. Bugbee, LEDs for photons, physiology and food, Nature, 563 (2018) 493-500.

[12] J.C. Sager, W. Giger, Re-evaluation of published data on the relative photosynthetic efficiency of intermittent and continuous light, Agricultural Meteorology, 22 (1980) 289-302.

[13] D.J. Tennessen, R.J. Bula, T.D. Sharkey, Efficiency of photosynthesis in continuous and pulsed light emitting diode irradiation, Photosynthesis Research, 44 (1995) 261-269.

[14] W.W. Garner, H.A. Allard, Effect of abnormally long and short alternations of light and darkness on growth and development of plants, United States Department of Agriculture, 1931.

[15] M.M. Neff, J. Chory, Genetic interactions between phytochrome A, phytochrome B, and cryptochrome 1 during Arabidopsis development, Plant Physiol, 118 (1998) 27-35.

[16] S.D. Carvalho, K.M. Folta, Sequential light programs shape kale (Brassica napus) sprout appearance and alter metabolic and nutrient content, Horticulture Research, 1 (2014) 1-13. 
[17] K. Li, Z. Li, Q. Yang, Improving Light Distribution by Zoom Lens for Electricity Savings in a Plant Factory with Light-Emitting Diodes, Frontiers in Plant Science, 7 (2016) 92.

[18] T. Kozai, G. Niu, Role of the Plant Factory with Artificial Lighting in Urban Areas

in: T. Kozai, G. Niu, T. Takagaki (Eds.) Plant Factory: An Indoor Vertical Farming System for Efficient Quality Plant Production, Academic Press, 2015, pp. 7-27.

[19] K.M. Folta, Breeding new varieties for controlled environments, Plant Biology, 21 (2019) 6-12.

[20] K. Li, Q.-C. Yang, Y.-X. Tong, R. Cheng, Using movable light-emitting diodes for electricity savings in a plant factory growing lettuce, Horttechnology, 24 (2014) 546-553.

[21] D. Ezer, J.-H. Jung, H. Lan, S. Biswas, L. Gregoire, M.S. Box, V. Charoensawan, S. Cortijo, X. Lai, D. Stöckle, C. Zubieta, K.E. Jaeger, P.A. Wigge, The evening complex coordinates environmental and endogenous signals in Arabidopsis, Nature Plants, 3 (2017) 17087.

[22] K.A. Hicks, T.M. Albertson, D.R. Wagner, EARLY FLOWERING3 Encodes a Novel Protein That Regulates Circadian Clock Function and Flowering in Arabidopsis, in: Plant Cell, 2001, pp. 1281-1292.

[23] D.A. Nusinow, A. Helfer, E.E. Hamilton, J.J. King, T. Imaizumi, T.F. Schultz, E.M. Farre, S.A. Kay, The ELF4-ELF3-LUX complex links the circadian clock to diurnal control of hypocotyl growth, Nature, 475 (2011) 398-402.

[24] S.X. Lu, C.J. Webb, S.M. Knowles, S.H.J. Kim, Z. Wang, E.M. Tobin, CCA1 and ELF3 Interact in the control of hypocotyl length and flowering time in Arabidopsis, Plant physiology, 158 (2012) 10791088.

[25] A. de Montaigu, M.C. Berns, G. Coupland, A Luciferase-Based Assay to Test Whether Gene Expression Responses to Environmental Inputs Are Temporally Restricted by the Circadian Clock, in: P. Duque (Ed.) Environmental Responses in Plants: Methods and Protocols, Springer New York, New York, NY, 2016, pp. 93-106.

[26] M.T. Boylan, P.H. Quail, Phytochrome a overexpression inhibits hypocotyl elongation in transgenic Arabidopsis, Proc Natl Acad Sci U S A, 88 (1991) 10806-10810.

[27] F.D. Beall, E.C. Yeung, R.P. Pharis, Far-red light stimulates internode elongation, cell division, cell elongation, and gibberellin levels in bean, Canadian Journal of Botany, 74 (1996) 743-752.

[28] H. Lange, W. Shropshire, H. Mohr, An Analysis of Phytochrome-mediated Anthocyanin Synthesis, Plant Physiology, 47 (1971) 649.

[29] B. Steinitz, E. Schäfer, H. Drumm, H. Mohr, Correlation between far-red absorbing phytochrome and response in phytochrome-mediated anthocyanin synthesis, Plant, Cell \& Environment, 2 (1979) 159-163.

[30] H. Drumm, H. Mohr, The dose response curve in phytochrome-mediated anthocyanin synthesis in the mustard seedling, Photochemistry and Photobiology, 20 (1974) 151-157.

[31] V. Herbel, C. Orth, R. Wenzel, M. Ahmad, R. Bittl, A. Batschauer, Lifetimes of Arabidopsis cryptochrome signaling states in vivo, The Plant Journal, 74 (2013) 583-592. 


\section{Figure 1}

\section{Anthocyanin (ng/g fw)}
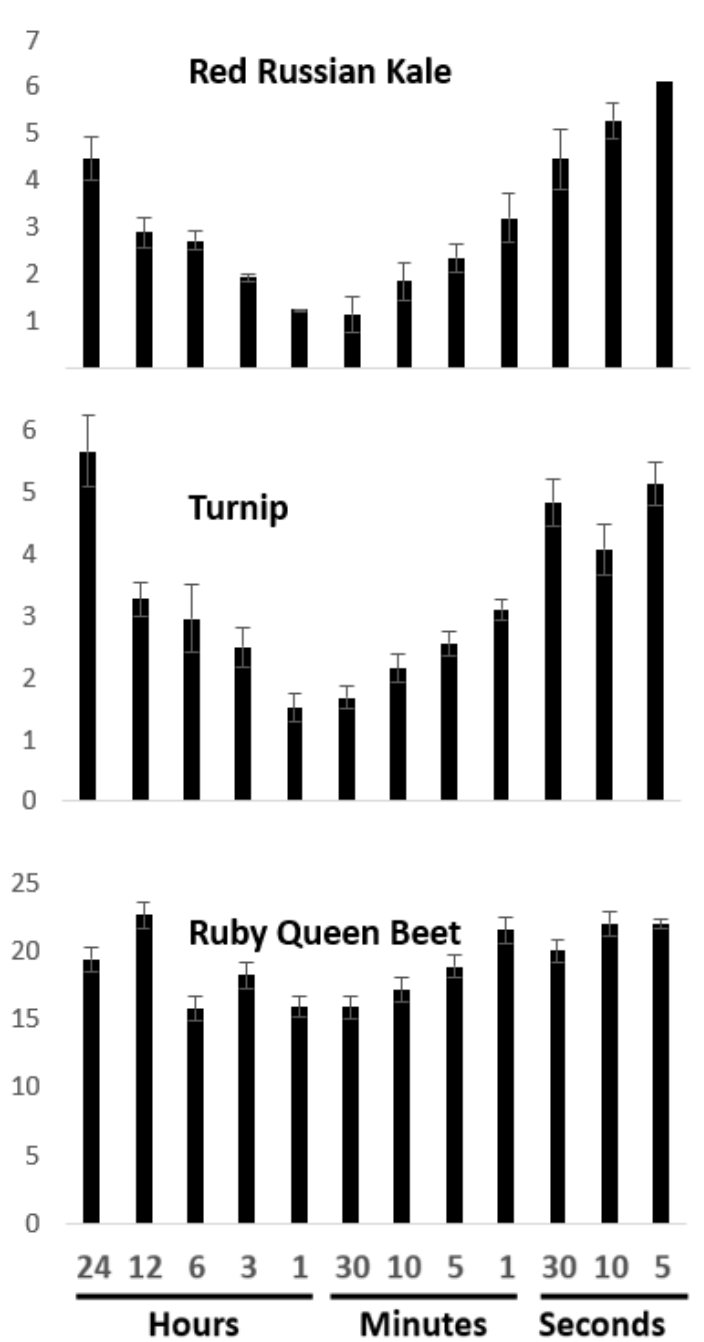

Hypocotyl length (mm)

35

30

25

20

15

10

5

0

35

30

25

20

15

10

5

0

20

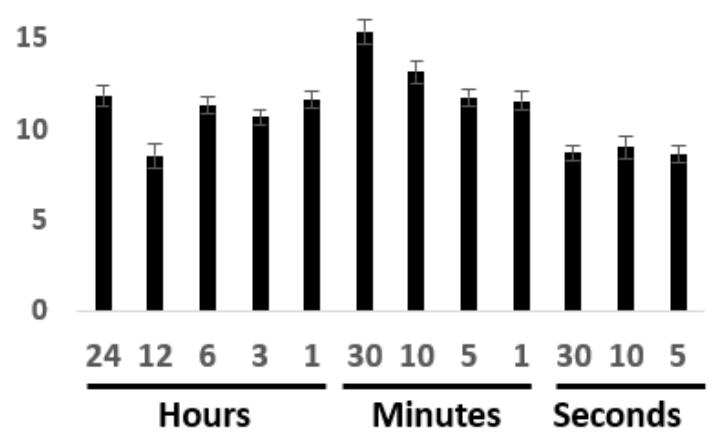



aCC-BY-ND 4.0 International license.

\section{Figure 2}
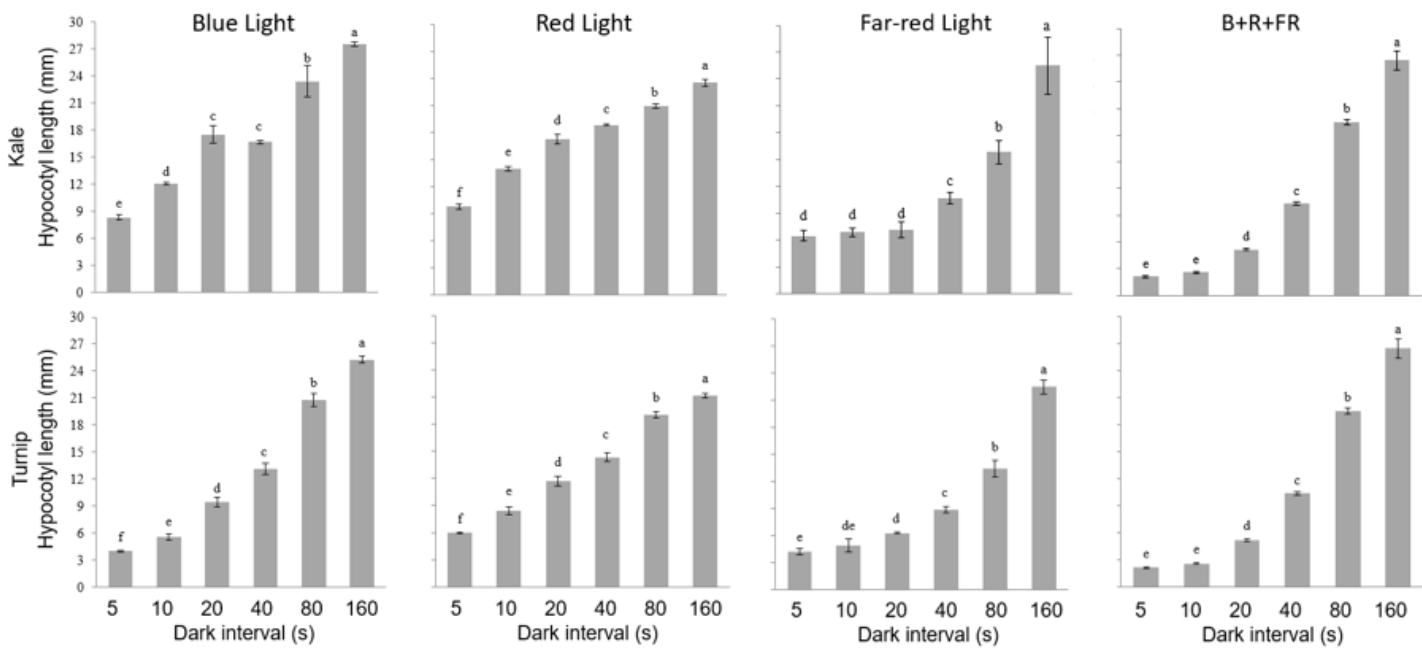


\section{Figure 3}

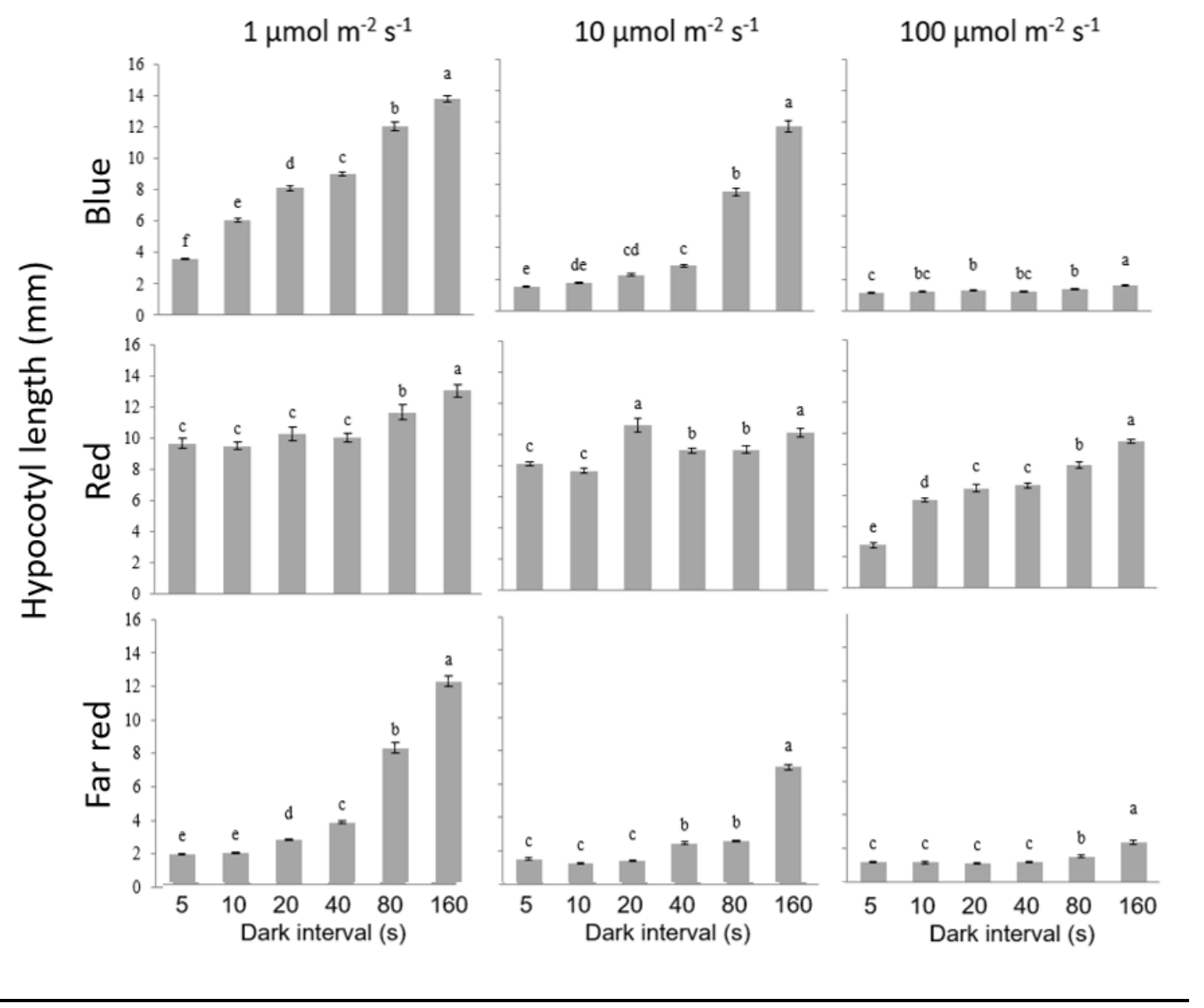




\section{Figure 4}

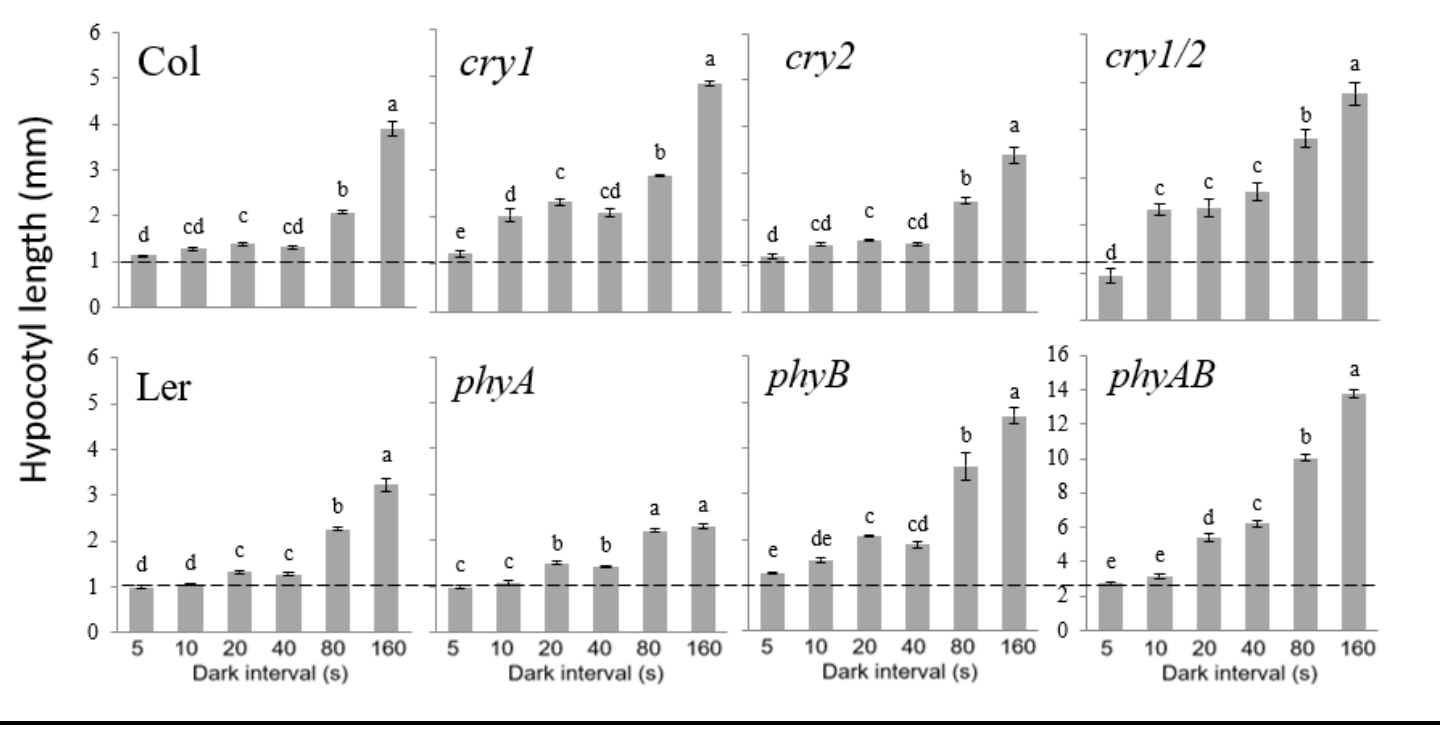


Supplemental Figure 1.
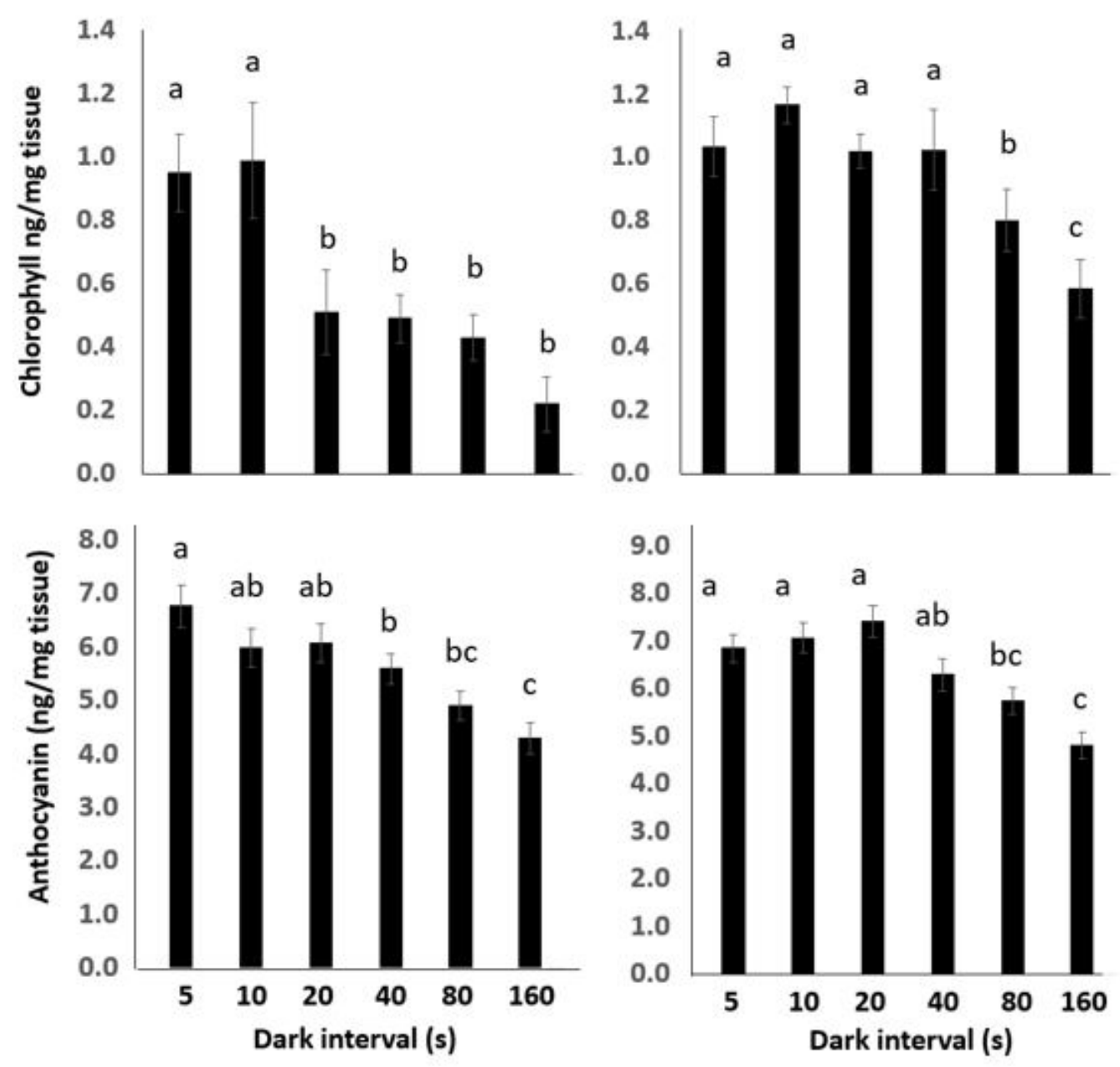